\title{
Isolate hypoglossal nerve palsy as a rare cause of cervical osteophyte
}

\author{
Filippo Manelli, ${ }^{1}$ Maria Sofia Cotelli, ${ }^{2}$ Marinella Turla, ${ }^{2}$ Paolo Donati, ${ }^{1}$ Mariachiara Michelini, ${ }^{2}$ Eugenio Atzeni, ${ }^{2}$ \\ Michele Briganti ${ }^{2}$
}

${ }^{1}$ Emergency and Urgency Department; and ${ }^{2}$ Neurology Unit, Valle Camonica Hospital, Esine (BS), Italy

\begin{abstract}
Isolated hypoglossal nerve palsy is rare, and etiological diagnosis is difficult. We report a case of a 64-year-old Caucasian woman, evaluated due to gradually progressive slurred speech and swallowing deficits, which was diagnosed for isolated hypoglossal compression by a cervical osteophyte.
\end{abstract}

\section{Introduction}

The hypoglossal nerve is a pure motor nerve that innervates the intrinsic and extrinsic muscles of the tongue. It can be damaged anywhere during its course. ${ }^{1}$ Isolate hypoglossal nerve palsy (IHP) is a rare finding; the literature reports multiple IHP etiologies, such as skull base tumor, trauma, vascular, joint, and autoimmune pathologies, infectious diseases; finally, in certain cases, no etiology can be determined. ${ }^{2} \mathrm{We}$ report the case of a 64-year-old woman, evaluated due to gradually progressive slurred speech and swallowing deficits, who was diagnosed with hypoglossal nerve palsy due to cervical osteophyte.

Correspondence: Filippo Manelli, Emergency and Urgency Department, Azienda Socio Sanitaria Territoriale Valle Camonica, via Manzoni 142, 25040 Esine (BS), Italy.

Tel. +39.0363.369274.

E-mail: f.manelli68@gmail.com

Key words: Hypoglossal; palsy; osteophyte; cervical; spine.

Contributions: the authors contributed equally.

Conflict of interests: the authors declare no potential conflict of interests.

Ethics approval: not required.

Informed consent: the patient gave her consent.

Received for publication: 13 August 2020.

Revision received: 25 August 2020.

Accepted for publication: 25 August 2020.

This work is licensed under a Creative Commons Attribution NonCommercial 4.0 License (CC BY-NC 4.0).

${ }^{\circ}$ Copyright: the Author(s), 2020

Licensee PAGEPress, Italy

Italian Journal of Medicine 2020; 14:245-246

doi:10.4081/itjm.2020.1358

\section{Case Report}

We evaluated a 64-year-old Caucasian woman due to gradually progressive slurred speech and swallowing deficits. Her past medical and her familiar history were unremarkable. Neurological examination showed tongue deviation to the left on protrusion, with left $12^{\text {th }}$ cranial nerve palsy (Figure 1, panel A). There was no involvement of $9^{\text {th }}, 10^{\text {th }}$ or $11^{\text {th }}$ cranial nerves. Brain magnetic resonance imaging (MRI) was unremarkable. Cervical MRI and computer tomography scan of the neck showed cervical osteophyte (C2) facing the left hypoglossal canal (Figure 1, panel B). Elettroneurography confirmed the isolate unexcitability of the left $12^{\text {th }}$ nerve with signs of active denervation and absent recruiting of motor units involving left tongue muscles. The neurosurgery approach was discussed, but then excluded due to surgical risk.

\section{Discussion}

The hypoglossal nerve or the twelfth cranial nerve is a pure motor nerve that controls both the intrinsic and extrinsic muscle of the tongue. ${ }^{3}$ Similar to the other cranial nerves, it is divided into three sections: supranuclear, nuclear, and infranuclear. Knowing how the tongue movement and coordination are affected allows clinicians to narrow down the cause of IHP. ${ }^{4}$ For instance, supranuclear lesions usually produce weakness of the contralateral side of the tongue, while nuclear or infranuclear pathology develops dysfunction of the hypoglossal nerve of the involved side, ${ }^{5}$ which eventually predisposes patients to tongue atrophy, deviation, and dysphagia. The hypoglossal nerve is divided into four to five segments based on its anatomical features. ${ }^{4}$ The nerve arises from its nucleus and exits the skull base through the hypoglossal foramen. The extracranial part runs lateral to the carotid artery and anterior to the upper cervical spine, and it finally innervates the tongue. ${ }^{6}$ The nerve can be damaged in every section in its trajectory. 

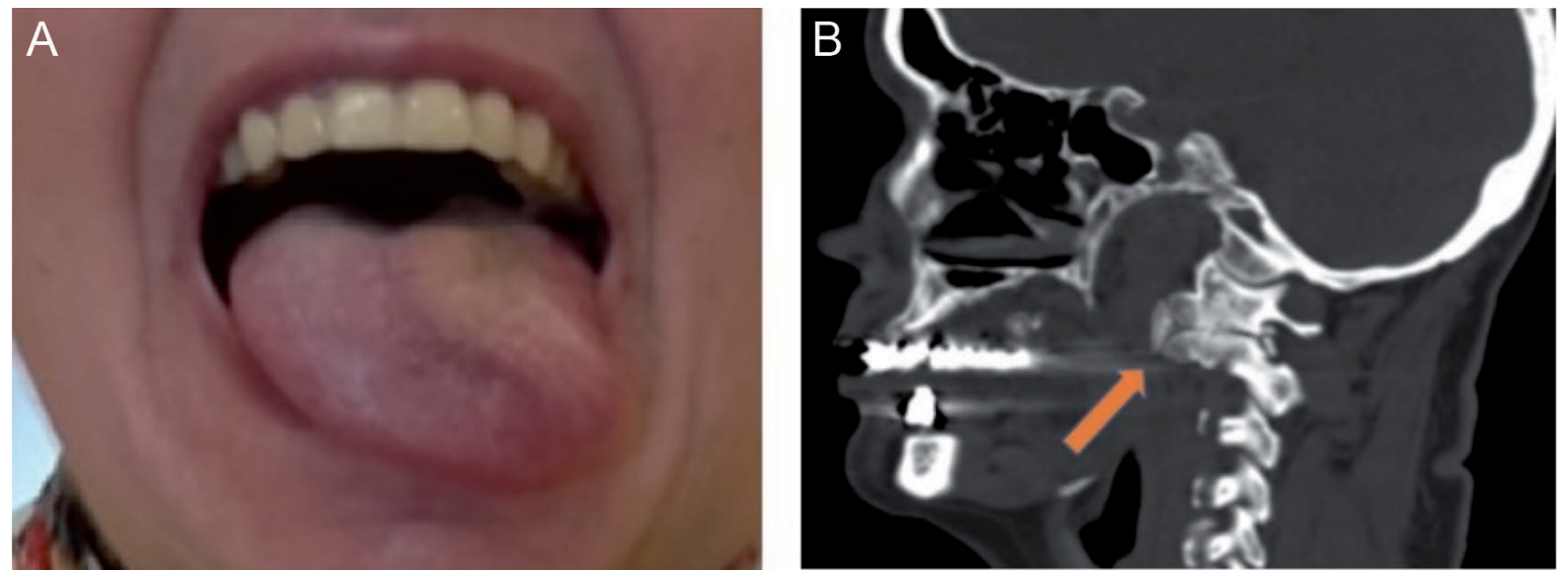

Figure 1. XII nerve palsy due to cervical osteophyte. A) Evidence of tongue deviation to the left on protrusion, with left $12^{\text {th }}$ cranial nerve palsy. B) Computer tomography scan of the neck showing cervical osteophyte (C2) facing the left hypoglossal canal.

Specifically, one study showed imaging features of the hypoglossal nerve by dividing it into four segments intra-axial, cisternal, skull base, and extracranial segments - and identified pathologies for each segment: vascular, neoplasia, infection/inflammation, trauma, and autoimmune. ${ }^{3}$

Hypoglossal nerve palsy secondary to craniocervical junction juxta-articular (synovial and ganglion) ${ }^{7}$ cysts and osteophytes has been described in isolated case reports; $; 8$ yet, these pathologies are not classically included in the differential diagnosis for hypoglossal palsy.

To our knowledge, only a few case reports have been published concerning isolated hypoglossal compression by osteophyte. ${ }^{8,9}$

\section{Conclusions}

Clinical examination should systematically concern the paired cranial nerves to rule out associated nerve damage. The Claude Bernard-Horner sign should be systematically looked for, being frequently associated with hypoglossal palsy in carotid dissection. ${ }^{9}$ The other most frequently associated cranial pairs are X, VII, and V. ${ }^{9}$ Once isolated involvement has established diagnosis of IHP, etiology is to be investigated. Onset circumstances are to be examined for trigger factors (cervical trauma, recent surgery) and predisposition (cardiovascular history, arthropathy, systemic illness, malignancy), to guide paraclinical assessment. ${ }^{9}$

Meticulous examination (cervical magnetic reso- nance imaging, high-resolution computer tomography scan of the skull base, MR angiogram in order to exclude a suspected vascular cause) constitutes the key to diagnose this rare cause of $12^{\text {th }}$ cranial nerve palsy. ${ }^{1}$

\section{References}

1. Patron V, Roudaut PY, Lerat J, et al. Isolated hypoglossal palsy due to cervical osteophyte. Eur Ann Otorhinolaryngol Head Neck Dis 2012;129:44-6.

2. Boban M, Brinar VV, Habek M, et al. Isolated hypoglossal nerve palsy: a diagnostic challenge. Eur Neurol 2007;58:177-81.

3. Thompson EO, Smoker WR. Hypoglossal nerve palsy: a segmental approach. Radiographics 1994;14:939-58.

4. Alves P. Imaging the hypoglossal nerve. Eur J Radiol 2010;74:368-77.

5. Walker HK. Cranial nerve XII: the hypoglossal nerve. In: H.K. Walker, W.D. Hall, and J.W. Hurst (eds.), Clinical Methods: The History, Physical, and Laboratory Examinations. 3rd edn. Boston: Butterworth Publishers Reed Publishing; 1990.

6. Islam S, Walton GM, Howe D. Aberrant anatomy of the hypoglossal nerve. J Laryngol Otol 2012;126:538-40.

7. Mujic A, Hunn A, Liddell J, et al. Isolated unilateral hypoglossal nerve paralysis caused by an atlanto-occipital joint synovial cyst. J Clin Neurosci 2003;10:492-5.

8. Patro SN, Torres C, Riascos R. An unusual case of isolated hypoglossal nerve palsy secondary to osteophytic projection from the atlanto-occipital joint. Neuroradiol J 2014;27:361-4.

9. Weindling SM, Goff RD, Wood CP, et al. Is hypoglossal nerve palsy caused by craniocervical junction degenerative disease an underrecognized entity? AJNR Am J Neuroradiol 2016;37:2138-43. 